\title{
Silicon Carbide Power Device Characterization for HEVs
}

\author{
Burak Ozpineci ${ }^{1,3}$ \\ burak@ieee.org \\ Leon M. Tolbert ${ }^{1,2}$ \\ tolbert@utk.edu \\ Syed K. Islam ${ }^{1}$ \\ sislam@utk.edu \\ ${ }^{1}$ Dept. of Electrical and Computer Engineering, The University of Tennessee, Knoxville, TN 37996-2100 \\ ${ }^{2}$ Oak Ridge National Laboratory, P.O. Box 2009, Oak Ridge, TN 37831-6472 \\ ${ }^{3}$ Oak Ridge Institute for Science and Education, Oak Ridge, TN 37831-0117
}

\begin{abstract}
The emergence of silicon carbide- (SiC-) based power semiconductor switches, with their superior features compared with silicon- (Si-) based switches, has resulted in substantial improvement in the performance of power electronics converter systems. These systems with $\mathrm{SiC}$ power devices have the qualities of being more compact, lighter, and more efficient; thus, they are ideal for high-voltage power electronics applications such as a hybrid electric vehicle (HEV) traction drive. More research is required to show the impact of $\mathrm{SiC}$ devices in power conversion systems. In this study, findings of $\mathrm{SiC}$ research at Oak Ridge National Laboratory (ORNL), including $\mathrm{SiC}$ device design and system modeling studies, are discussed.
\end{abstract}

\section{INTRODUCTION}

Presently, almost all the power electronics converter systems use silicon- (Si-) based power semiconductor switches. The performance of these switches is approaching the theoretical limits of the Si material. Another material, silicon carbide ( $\mathrm{SiC}$ ), with superior properties compared with $\mathrm{Si}$, is a good candidate to be used in the next generation of power devices.

SiC power devices, with their close-to-ideal characteristics, bring great performance improvement to power converter applications. Some of these advantages compared with Sibased power devices are as follows:

- $\mathrm{SiC}$ unipolar devices are thinner, and they have lower on-resistances. At low breakdown voltages $(\sim 50 \mathrm{~V})$, these devices have specific on-resistances of $1.12 \mu \Omega$, around 100 times less than those of their Si counterparts. At higher breakdown voltages $(\sim 5000 \mathrm{~V})$, the onresistance goes up to $29.5 \mathrm{~m} \Omega$, but it still is 300 times less than that of the comparable Si devices [1]. With lower $R_{o n}$, SiC power devices have lower conduction losses; therefore, the converters have higher overall efficiency.

- SiC-based power devices have higher breakdown

Prepared by the Oak Ridge National Laboratory, Oak Ridge, Tennessee 37831, managed by UT-Battelle for the U.S. Department of Energy under contract DE-AC05-00OR22725.

The submitted manuscript has been authored by a contractor of the U.S. Government under Contract No. DE-AC05-00OR22725. Accordingly, the U.S. Government retains a non-exclusive, royalty-free license to publish from the contribution, or allow others to do so, for U.S. Government purposes. voltages because of their higher electric breakdown field; for example, Si Schottky diodes are commercially available typically at voltages lower than $300 \mathrm{~V}$, but the first commercial SiC Schottky diodes are already rated at $600 \mathrm{~V}$.

- $\mathrm{SiC}$ has a higher thermal conductivity $(4.9 \mathrm{~W} / \mathrm{cm} \cdot \mathrm{K}$ for $\mathrm{SiC}$ and $1.5 \mathrm{~W} / \mathrm{cm} \cdot \mathrm{K}$ for $\mathrm{Si}$ ), and $\mathrm{SiC}$ power devices have a lower junction-to-case thermal resistance, $R_{t h-j c}(0.02$ $\mathrm{K} / \mathrm{W}$ for $\mathrm{SiC}$ and $0.06 \mathrm{~K} / \mathrm{W}$ for $\mathrm{Si}$ ); thus device temperature increase is slower.

- $\mathrm{SiC}$ devices can operate at high temperatures. $\mathrm{SiC}$ device operation at up to $600^{\circ} \mathrm{C}$ is mentioned in the literature [2]. Si devices, on the other hand, can operate at a maximum junction temperature of only $150^{\circ} \mathrm{C}$.

- $\quad \mathrm{SiC}$ is extremely radiation hard; that is, radiation does not degrade the electronic properties of $\mathrm{SiC}$.

- Forward and reverse characteristics of $\mathrm{SiC}$ power devices vary only slightly with temperature and time; therefore, they are more reliable.

- SiC-based bipolar devices have excellent reverse recovery characteristics [3]. With less reverse recovery current, the switching losses and EMI are reduced, and there is less or no need for snubbers.

- Because of low switching losses, SiC-based devices can operate at higher frequencies $(>20 \mathrm{kHz})$ not possible with Si-based devices in power levels of more than a few tens of kilowatts.

Although $\mathrm{SiC}$ has these advantages compared with $\mathrm{Si}$, the present disadvantages limit its widespread use. Some of these disadvantages are

- Low processing yield because of micropipes. The best wafers available have $<1 / \mathrm{cm}^{2}$, but they are more expensive than the typical wafer with $<10 / \mathrm{cm}^{2}$.

- High cost-\$7 for a $600 \mathrm{~V}, 4$ A Schottky diode (a similar Si pn diode is $<<\$ 1)$.

- Limited availability (only Schottky diodes at relatively low power are commercially available).

- Need for high-temperature packaging techniques that have not yet been developed. 


\section{SYSTEM MODELING}

The main objective of system modeling is to show some of the system-level benefits of using $\mathrm{SiC}$ devices in power converter applications, such as the large reduction in the size, weight, and cost of the power conditioning and/or thermal management systems. The selected system for this study is a hybrid electric vehicle (HEV) traction drive. A typical electric traction drive schematic for an HEV is shown in Fig. 1. The schematic consists of a battery, a three-phase inverter (dc/ac converter), and an induction motor.

To evaluate any transportation system, its operation while the vehicle is accelerating, decelerating, stopped, etc., should be considered. For this reason, it is necessary to simulate the $\mathrm{HEV}$ and observe the response of the traction drive over a driving cycle. Using ADVISOR (ADvanced VehIcle SimulatOR), an HEV model was simulated in ADVISOR over the Federal Urban Driving Schedule (FUDS), which is a standard 1369-second velocity profile of an average person's vehicle on the way to work [7].

The inverter, in this study, uses sinusoidal PWM with a switching frequency of $20 \mathrm{kHz}$. The induction motor is rated at $31 \mathrm{~kW}, 230 \mathrm{~V}$, 4-pole, $3000 \mathrm{rpm}$. The peak current passing through the switches is $136 \mathrm{~A}$, and the peak voltage across them is the battery voltage $V_{d c}$, which is $300 \mathrm{~V}$ in this case. Therefore, the MOSFETs and diodes have to be rated at least $400 \mathrm{~V}$ and $200 \mathrm{~A}$. The Si MOSFETs are not available in this power range, and $\mathrm{SiC}$ MOSFETs are not yet available. For comparison purposes in this study, we will assume that $\mathrm{Si}$ MOSFETs exist at high power, too. Note that the drive is controlled by constant $\mathrm{V} / \mathrm{Hz}$ control.

The following section will explain the device loss modeling approach [8].

\section{DiOde ModELING}

\section{A. Conduction losses:}

The circuit in Fig. 2 is built to find the $I-V$ characteristics of the diodes. The dc voltage supply is varied, and the diode forward voltage and current are measured. This test is carried out at several temperatures of up to $250^{\circ} \mathrm{C}$.

The results for both $\mathrm{Si}$ pn and $\mathrm{SiC}$ Schottky diodes are given in Fig. 3, in which it can be seen that the forward voltage of the $\mathrm{SiC}$ diode is higher than that of the Si diode. This is expected because of SiC's wider bandgap. Another difference between these two diodes is their high-temperature

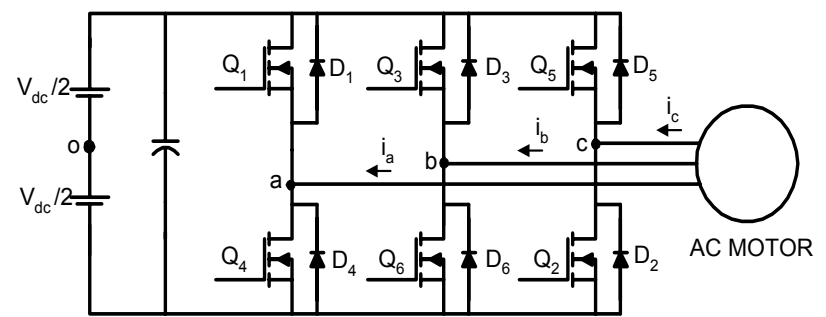

Fig. 1. Electric traction drive. behavior. As the temperature increases, the forward characteristics of the Si diode change severely, while those of the $\mathrm{SiC}$ diode stay confined to a narrow region. Note that the pn diode (negative) and the Schottky diode (positive) have different polarity temperature coefficients; that is why the slope of the curve at higher currents is increasing in the $\mathrm{Si}$ diode case and decreasing in the $\mathrm{SiC}$ diode case with the temperature increase.

For the traction drive application, the forward characteristics of $200 \mathrm{~A}$ rated diodes are required. Assume that the $200 \mathrm{~A}$ diode is equivalent to twenty $10 \mathrm{~A}$ diodes connected in parallel. Then, in the $I-V$ characteristics of the resulting diode, $I_{s}$ and $R_{s}$ should be changed accordingly.

The diode equation is

$I=I_{s}\left(e^{q\left(V-I R_{S}\right) / n k T}-1\right)$.

$I_{S}$ is directly and $R_{S}$ is inversely proportional to the area of the device. For the $200 \mathrm{~A}$ diode, the area is increased 20 times; therefore, $I_{S}$ increases 20 times and $R_{S}$ decreases 20 times. The resulting diode equation is

$I=20 \times I_{s}\left(e^{q\left(V-I \frac{R_{S}}{20}\right) / n k T}-1\right)$.

If a line is drawn along the linear high-current portion of the $I-V$ curves of (2) extending to the $\mathrm{x}$-axis, the intercept on the $\mathrm{x}$-axis is $V_{D}$ and the slope of this line is $1 / R_{D}$. After these parameters are obtained for each diode at different operation temperatures, as shown in Fig. 4, the conduction losses can

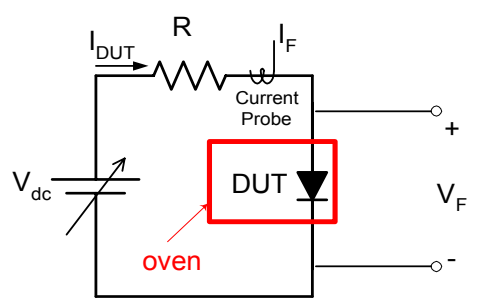

Fig. 2. I- $V$ characterization circuit.

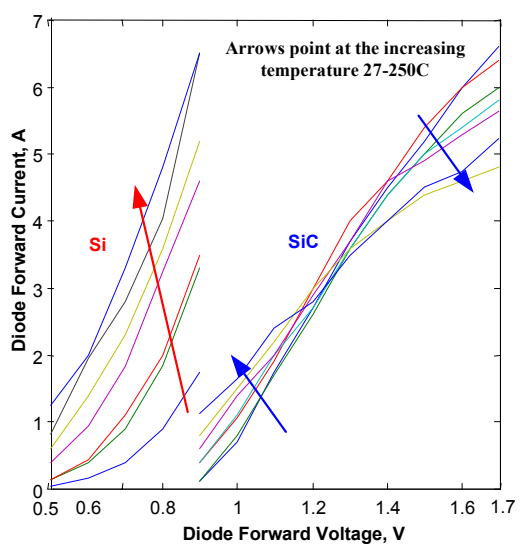

Fig. 3. Experimental $I-V$ characteristics of the $\mathrm{Si}$ and $\mathrm{SiC}$ diodes in an operating temperature range of $27 \mathrm{C}$ to $250^{\circ} \mathrm{C}$. 


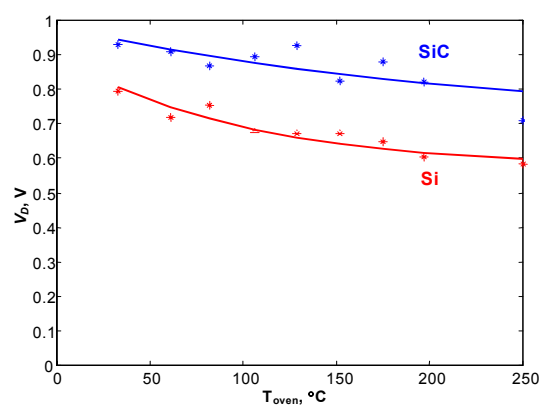

(a)

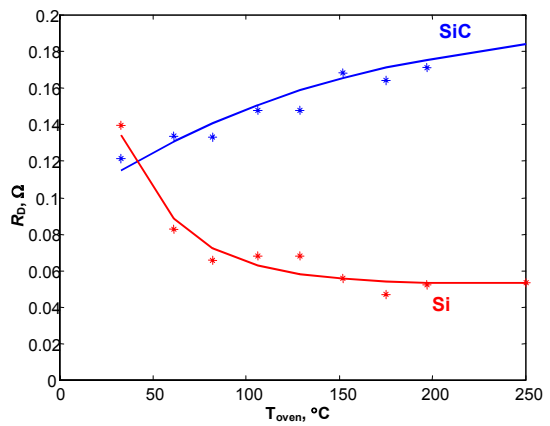

(b)

Fig. 4. Variation of (a) $V_{D}$ and (b) $R_{D}$ with temperature.

be calculated using (3) [8]:

$$
P_{\text {cond }, D}=I^{2} \cdot R_{D} \cdot\left(\frac{1}{8}-\frac{1}{3 \pi} M \cos \phi\right)+I \cdot V_{D} \cdot\left(\frac{1}{2 \pi}-\frac{1}{8} M \cos \phi\right)
$$

where $M$ is the modulation index and $\phi$ is the power factor.

The conduction losses for a $\mathrm{SiC}$ diode and for a $\mathrm{Si}$ diode are plotted in Figs. 5 and 6, respectively. These plots show that for low temperatures $\left(T<55^{\circ} \mathrm{C}\right)$, the conduction loss of

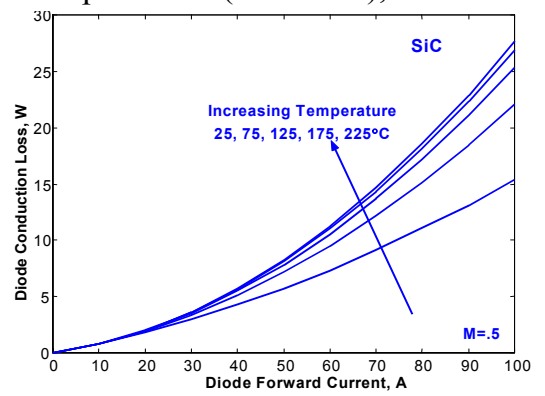

Fig. 5. Conduction losses for a 200A SiC diode.

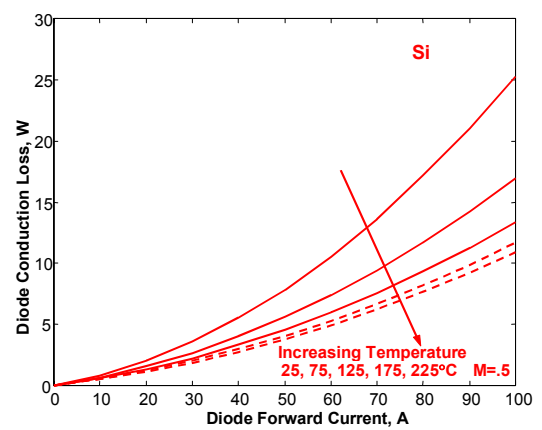

Fig. 6. Conduction losses for a 200A Si diode.

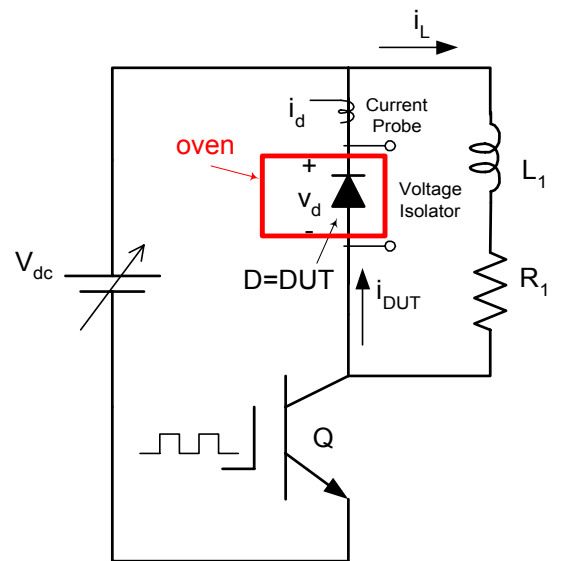

Fig. 7. Reverse recovery loss measurement circuit.

the $\mathrm{SiC}$ diode is less than that of the $\mathrm{Si}$ diode, and vice versa for higher temperatures $\left(T>55^{\circ} \mathrm{C}\right)$. This is because the series resistance of the Schottky diode is increasing while that of the pn diode is decreasing. This increase seems to be a disadvantage in the SiC Schottky diode case; however, note that the $\mathrm{Si}$ diode cannot withstand temperatures of over $150^{\circ} \mathrm{C}$.

\section{B. Switching losses:}

The most important part of the diode switching loss is the reverse recovery loss. The rest of the losses are negligible. Reverse recovery losses, in this paper, will be calculated experimentally.

For this purpose, the chopper circuit in Fig. 7 was built. The main switch $\mathrm{Q}$ is turned on and off at $1 \mathrm{kHz}$ with a duty ratio of $75 \%$. When $\mathrm{Q}$ is on, the diode $\mathrm{D}$ is off, and the current is forced by the dc supply to build up through the load and Q. When Q turns off, the load current starts flowing through D and the load. In this mode, the dc supply is out of the loop; therefore, the current starts decreasing. After a while, Q is turned on again and then D turns off. The typical diode turn-off waveforms are given in Fig. 8. These experimental waveforms show that the $\mathrm{Si}$ diode switching losses are almost three times more than those of the $\mathrm{SiC}$

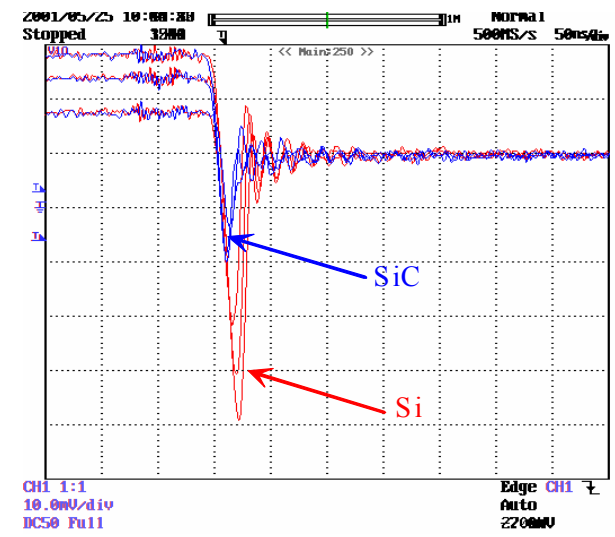

Fig. 8. Typical reverse recovery waveforms of the Si pn and SiC Schottky diode for different forward current values $(2 \mathrm{~A} / \mathrm{div}$.). 
diode.

The peak reverse recovery current, $I_{R}$, and the switching loss, $P_{s w}$, of the diodes are measured at different operating temperatures with varying load currents. The results are plotted in Figs. 9 and 10. In Fig. 9, the $I_{R}$ of the Si diode is higher than that of the $\mathrm{SiC}$ diode at any operating temperature. As the temperature increases, the difference increases because the $I_{R}$ of the $\mathrm{Si}$ diode increases with temperature, but that of the $\mathrm{SiC}$ diode stays constant. Note that the Si diode failed when operating at $150^{\circ} \mathrm{C}$ and $4.5 \mathrm{~A}$, while the $\mathrm{SiC}$ diode survived that temperature and failed at a higher $250^{\circ} \mathrm{C}$ and $4 \mathrm{~A}$.

To obtain a 200 A diode model for the traction drive, assume as before that 20 of the diodes tested here are connected in parallel to form a 200 A diode. The switching losses multiplied by 20 gives the switching losses of the 200 $\mathrm{A} \mathrm{Si}$ and $\mathrm{SiC}$ diodes (Fig. 10).

\section{MOSFET MODELING}

There are presently no commercially available $\mathrm{SiC}$ MOSFETs; therefore, it is not possible to obtain an experimental model of a SiC MOSFET. In this study, for the modeling purposes, averaged MOSFET loss equations over the FUDS cycle are derived in [8] and are given below.

MOSFET conduction losses

$P_{\text {cond }, Q 1}=I_{Q 1, r m s}^{2} \cdot R_{D S, o n}$.

MOSFET switching losses

$$
\begin{aligned}
P_{s w, Q 1}= & \frac{D f_{C}}{2 \pi}\left[\frac{C_{1}}{\sqrt{C_{1}^{2}-J^{\prime 2}}}\left(\pi+2 \tan ^{-1}\left(\frac{J^{\prime}}{\sqrt{C_{1}^{2}-J^{\prime 2}}}\right)\right)\right. \\
& \left.+\frac{C_{2}}{\sqrt{C_{2}^{2}-J^{\prime 2}}}\left(-\pi+2 \tan ^{-1}\left(\frac{J^{\prime}}{\sqrt{C_{2}^{2}-J^{\prime 2}}}\right)\right)\right]
\end{aligned}
$$

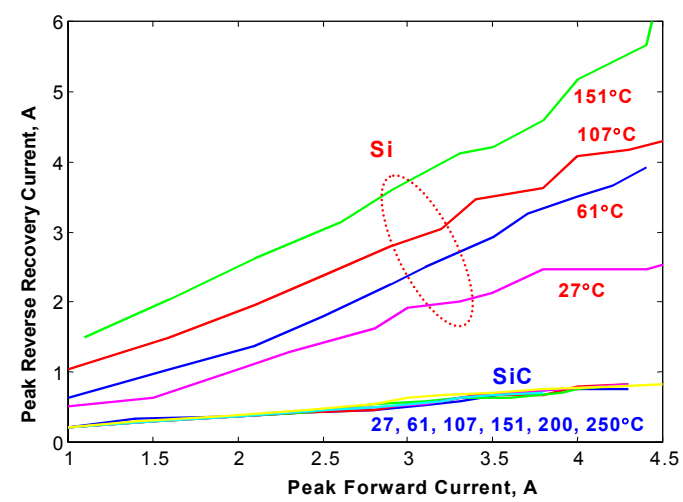

Fig. 9. Peak reverse recovery values with respect to the forward current at different operating temperatures.

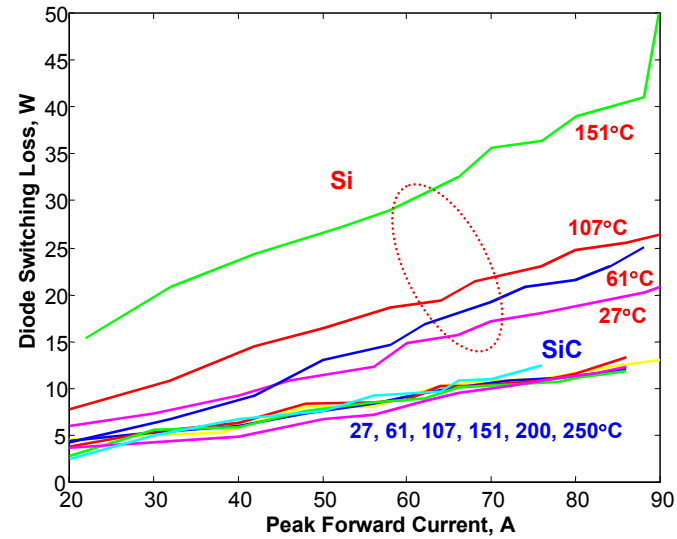

Fig. 10. Diode switching loss of 200A diode at different operating temperatures.

\section{RESULTS}

The HEV traction drive is simulated over the FUDS cycle using the model developed in the previous sections. The loss profiles of a diode and a MOSFET in the drive are shown in Fig. 11. SiC diode losses are lower than Si diode losses mostly because the $\mathrm{SiC}$ diode has lower reverse recovery losses. On the other hand, SiC MOSFET losses are lower because the switching losses are similar but SiC MOSFET conduction losses are lower. The reason for lower conduction losses is the lower specific on-resistance [1] $\left(R_{o n, s p(\mathrm{Si})}=180 \times 10^{-3} \Omega-\mathrm{cm}^{2}, R_{o n, s p(4 H-S i C)}=0.3 \times 10^{-3} \Omega-\mathrm{cm}^{2}\right)$.

Total energy loss (six diodes and six MOSFETs) is 0.351 $\mathrm{kW} \cdot \mathrm{hr}$ for the Si inverter and $0.129 \mathrm{~kW} \cdot \mathrm{hr}$ for the $\mathrm{SiC}$ inverter over the FUDS cycle. The corresponding efficiency (Fig. 12) of the $\mathrm{Si}$ inverter is $80-85 \%$, while that of the $\mathrm{SiC}$ inverter is $90-95 \%$. This is a 10 percentage points increase in the average efficiency. As a result, the battery in the HEV with the $\mathrm{SiC}$ inverter will need less charging than the one with the Si inverter.

The loss profiles in Fig. 11 are fed to the thermal models of the devices. The resulting junction temperature profiles are shown in Fig. 13. Natural air-cooled heatsinks are used to limit the junction temperature to $150^{\circ} \mathrm{C}$ for $\mathrm{Si}$ and $175^{\circ} \mathrm{C}$ for $\mathrm{SiC}$. The latter temperature limit is found on the datasheet of the Infineon SiC Schottky diode used in this study [9]. The resulting heatsink masses for each device and each inverter are given in Fig. 14. Using $\mathrm{SiC}$ devices instead of their Si counterparts in an HEV traction drive reduces the size and weight of the heatsink to one-third. Note that a heatsink usually occupies one-third the volume of the converter and weighs more than the electronics. 

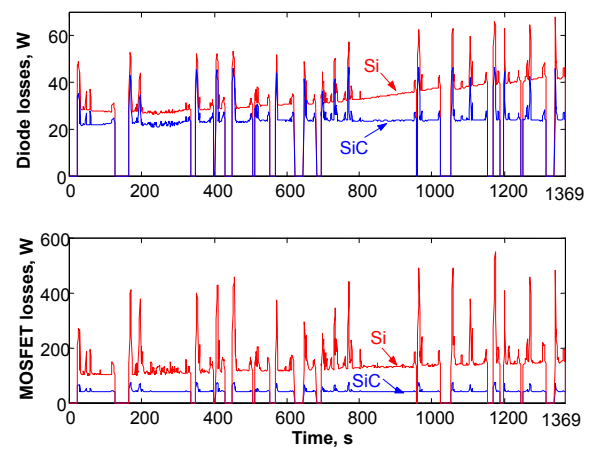

Fig. 11. Total loss profile for a diode (top) and a MOSFET (bottom).
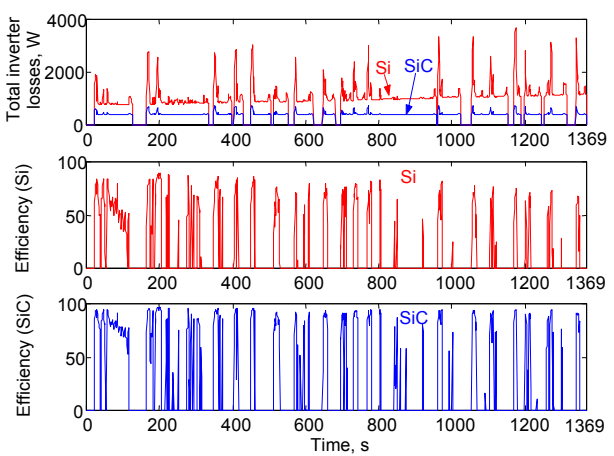

Fig. 12. Total losses and the efficiency of the inverter over the FUDS cycle.
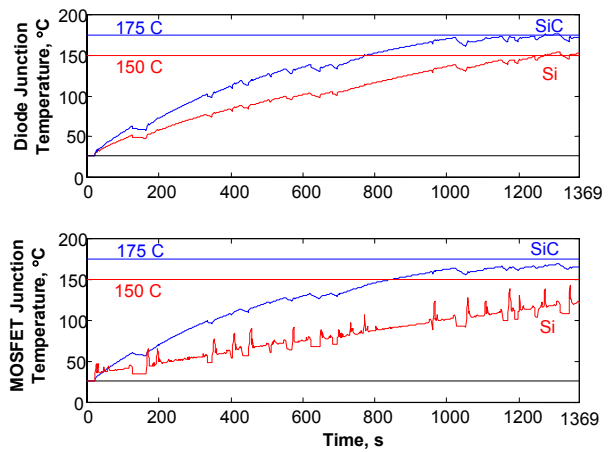

Fig. 13. Junction temperature profiles of the diodes and MOSFETs in the three-phase inverter.

Theoretically, SiC devices can work at higher temperatures. If new packaging techniques are developed so that these higher temperatures could be used as the junction temperature limits, then the amount of cooling required would be less, and more weight and volume savings would be possible.

\section{CONCLUSIONS}

Even the first $\mathrm{SiC}$ devices show the superiority of $\mathrm{SiC}$ compared with $\mathrm{Si}$. System studies show that power electronics systems using $\mathrm{SiC}$ power devices are on average

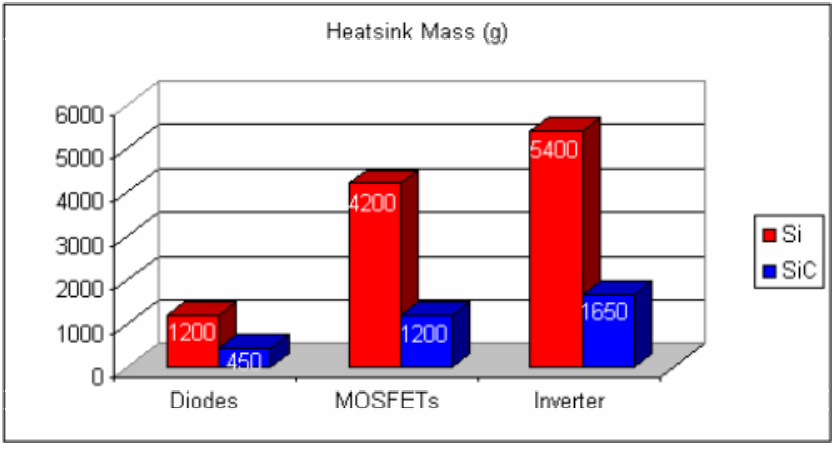

Fig. 14. The mass of the required heatsink for each device and inverter

10 percentage points more efficient because of the low losses of the $\mathrm{SiC}$ power devices. Moreover, with their hightemperature operation capability, they have less stringent cooling requirements. In the $\mathrm{HEV}$ traction drive studied here, using $\mathrm{SiC}$ power devices saves $1392 \mathrm{~cm}^{3}$ of space and 3.75 $\mathrm{kg}$ of weight.

The weight reduction and efficiency increase result in an increase in the fuel economy of the vehicle and a longer lifetime for the battery.

Note that $\mathrm{SiC}$ technology is still in its infancy. More studies like the one detailed in this paper are required to forecast the impact of $\mathrm{SiC}$ power devices. When this technology matures, for power devices in the medium-to-high power range, the future will be $\mathrm{SiC}$.

\section{REFERENCES}

[1] M. Bhatnagar and B. J. Baliga, "Comparison of 6H-SiC, 3C-SiC, and Si for power devices," IEEE Trans. on Electron Devices, 40 (3), pp. 645-655, March 1993.

[2] K. Shenai, R. S. Scott, and B. J. Baliga, "Optimum semiconductors for high-power electronics," IEEE Transactions on Electron Devices, 43 (9), pp. 1811-1823, Sept. 1989.

[3] A. Elasser, M. Kheraluwala, M. Ghezzo, R. Steigerwald, N. Krishnamurthy, J. Kretchmer, and T. P. Chow, "A comparative evaluation of new silicon carbide diodes and state-of-the-art silicon diodes for power electronic applications," IEEE IAS Annual Meeting Conference Proceedings, pp. 341-345, 1999.

[4] B. J. Baliga, Modern Power Devices, Wiley, New York, 1987.

[5] D. A. Grant and J. Gower, Power MOSFETs: Theory and Application, Wiley, New York, 1989.

[6] M. Darwish, "Study of the quasi-saturation effect in VDMOS transistors", IEEE Transactions on Electron Devices, vol. ED-33 (11), pp. 1710-1716, 1986.

[7] http://www.ctts.nrel.gov/analysis/advisor.html

[8] B. Ozpineci, L. M. Tolbert, S. K. Islam, and Md. Hasanuzzaman, "Effects of silicon carbide (SiC) power devices on PWM inverter losses," The Annual Conference of the IEEE Industrial Electronics Society (IECON'01), pp. 1187-1192, 2001.

[9] http://www.infineon.com/cgi/ecrm.dll/ecrm/scripts/prod_cat.jsp?oid=868 